\title{
KẾT QUẢ ĐIỀU TRI PHẪU THUÂTT CỦA GLÔCÔM GÓC ĐÓNG NGUYÊN PHÁT
}

\section{TÓM TẮT.}

Mục tiêu: Đánh giá đă̆c điểm lâm sàng, cận lâm sàng, kết quả điều trị phẫu thuật Glôcôm góc đóng nguyên phát. Đối tượng và phương pháp nghiên cứu: Mô tả, tiến cứu, có can thiêp lâm sàng không nhóm chứng, tiến hành trên 41 mắt Glôcôm góc đóng nguyên phát được phẫu thuật cắt bè củng giác mac hoặc laser cắt mống mắt chu biên tại Bệnh viện Mắt Nghệ An từ tháng 1/2021 đến tháng 4/2021. Kết quả: Bệnh nhân trên 60 tuổi $(73,4 \%)$, bệnh nhân nữ chiếm $66,7 \%$. Triệu chứng cơ năng chủ yếu: nhìn mờ (90\%) và đau nhức $(93,3 \%)$. Triệu chứng thực thể chủ yếu là tiền phòng nông $(100 \%)$, nhãn áp trung bình trước mổ là $21 \pm 3,9 \mathrm{mmHg}$. Cận lâm sàng chụp OCT: mức độ lõm đĩa > 0,3 chiếm 83,8\%. Sau phẫu thuật 1 tháng: thị lực ổn định hoăc tăng ít, không có trường hợp nào giảm thị lực so với trước phấu thuật. Nhãn áp sau mổ còn $17,4 \pm 1,1 \mathrm{mmHg}$. Không ghi nhận các biến chứng trong và sau mổ. Điều trị phâuu thuật hạ nhãn áp là phương pháp điều trị hiêuu quả và an toàn. laser

Tư khóa: Glôcôm góc đóng nguyên phát, cắt bè,

\section{SUMMARY}

\section{SURGICAL RESULTS OF PRIMARY ANGLE - CLOSURE GLAUCOMA}

Objectives: To describe the clinical \& paraclinical features and surgical results of primary angle - closure glaucoma. Subjects and methods: Prospective corelation study. Trabeculectomy or laser peripheral irdectomy was performed on 41 eyes of primary angle - closure glaucoma at Eye Hospital of Nghe An province from January 2021 to April 2021. Results: patients who were over 60 years old made up $73.4 \%$, the majority of the subjects were female $66,7 \%$. The physical symptoms included blurred vision (90\%) and painful eyes (93.3\%). The functional symptoms are mainly shallow anterior chamber (100\%), the mean IOP: $21 \pm 3,9 \mathrm{mmHg}$. Optical Coherence Tomography: $C / D>0.3(83,8 \%)$. One month of post-operation: decreasing visual acuity (0\%), the visual acuitis were remainded or increased in all most of cases. The mean preoperative intraocular pressure (IOP) was $17,4 \pm 1,1 \mathrm{mmHg}$. No complication is on operation or postoperation. Trabeculectomy and Laser peripheral irdectomy were effective and safe to decrease IOP.

Key words: Primary angle closure Glaucoma, Trabeculectomy, Laser.

\footnotetext{
${ }^{1}$ Bệnh viện Mắt Nghệ An

${ }^{2}$ Trường đai hoc y khoa Vinh

Chịu trách nhiệm chính: Trần Tất Thắng

Email: Thangmatna@gmail.com

Ngày nhận bài: 10.8.2021

Ngày phản biên khoa hoc: 4.10.2021

Ngày duyệt bài: 15.10.2021
}

Trần Tất Thắng ${ }^{1}$, Trịnh Thị Hà ${ }^{2}$

\section{I. ĐĂT VẤN ĐỀ}

Glôcôm là căn bênh gây mù lòa đứng thứ 2 trên thế giới cũng như ở Việt Nam và đây là mối đe dọa nguy hiểm đối với sức khỏe cộng đồng [1],[2]. Theo Tổ chức $Y$ tế Thế giới đến năm 2020 có khoảng 80 triêu người mắc bênh Glôcôm, trong đó có 11,2 triệu người mù lòa do bệnh này [1]. Chẩn đoán sớm và điều trị kịp thời cho bênh nhân giúp giảm thiểu tỷ lệ mù lòa. Phương pháp điều trị Glôcôm góc đóng nguyên phát chủ yếu bằng phẫu thuật, có rất nhiều loại phẫu thuật điều trị Glôcôm tuy nhiên hiện nay cắt bè củng giác mac và cắt mống mắt chu biên là được sử dung rộng rãi nhất, đặc biệt là laser cắt mống mắt chu biên ngày càng được ưu tiên lựa chọn và tính hiệu quả . Nghiên cứu thực hiện tại Bênh viện Mắt Nghệ An phẫu thuật Glôcôm góc đớng nguyên phát với mục tiêu Mô tả đăc điểm lâm sàng, cận lâm sàng và đánh giá kết quả điều trị Glôcôm góc đóng nguyên phát bằng phẫu thuật.

\section{II. ĐỐI TƯƠNG VÀ PHƯƠNG PHÁP NGHIÊN CỨU}

2.1. Đối tượng nghiên cứu. 30 bệnh nhân với 41 mắt Glôcôm góc đóng nguyên phát điều trị phẫu thuật tại Bệnh viện Mắt Nghệ An tù̀ tháng 1/2021- 4/2021 đủ tiêu chuẩn tham gia nghiên cứu.

2.2. Phương pháp nghiên cứu. Phương pháp mô tả, tiến cứu tất cả các trường hợp Glôcôm góc đóng nguyên phát được điều trị bằng phẩu thuật.

\section{Tiến hành khám bệnh:}

- Đo thị lực bằng bảng Landolt

- Đo nhãn áp bằng nhãn áp Maclakov

- Khám bằng kính sinh hiển vi: Đánh giá độ sâu góc tiền phòng, đánh giá độ mở góc tiền phòng theo phân loại Shaffer.

\section{Làm các cận lâm sàng:}

- Chụp cắt lớp võng mạc OCT: Đánh giá tỷ lệ Iõm/ đĩa, độ dày lớp sợi thần kinh quanh gai

- Làm các xét nghiêm cơ bản trước phẫu thuật.

Phương pháp phẫu thuật: Cắt bè củng giác mạc hoặc laser mống mắt chu biên dựa vào kết quả của khám lâm sàng và cận lâm sàng.

Theo dõi bệnh nhân trong phẫu thuật, thời gian hậu phẫu sau 1 ngày, 1 tuần và 1 tháng.

\subsection{Biến số nghiên cứu}

- Thông tin chung về đối tượng nghiên cứu 
- Đặc điểm lâm sàng của bệnh Glôcôm góc đóng nguyên phát

- Đánh giá kết quả phẫu thuật

2.4 Xử lí số liệu Bằng SPSS 20.0

\section{KẾT QUẢ NGHIÊN CỨU}

3.1. Đặc điểm chung của đối tượng nghiên cứu trước phẫu thuật

Bảng 1. Đặc điểm chung bệnh nhân

\begin{tabular}{|c|c|c|c|}
\hline \multicolumn{2}{|c|}{ Đặc điếm } & n & $\mathbf{( \% )}$ \\
\hline \multirow{4}{*}{ Nhóm tuổi } & $<40$ & 1 & 3.3 \\
\cline { 2 - 4 } & $40-49$ & 3 & 10 \\
\cline { 2 - 4 } & $50-59$ & 4 & 13,3 \\
\cline { 2 - 4 } & $60-69$ & 11 & 36,7 \\
\cline { 2 - 4 } & $>70$ & 11 & 36,7 \\
\hline \multirow{2}{*}{ Giới } & Nam & 10 & 33,3 \\
\cline { 2 - 4 } & Nữ & 20 & 66,7 \\
\hline
\end{tabular}

Glôcôm góc đóng nguyên phát hay gặp nhất ở nhóm tuổi già trên 60 tuổi, chiếm tî lệ là $73,4 \%$, độ tuổi trung bình là $64,2 \pm 10,7$ tuổi, nhỏ nhất là 39 tuổi lớn tuổi nhất là 81 tuổi.

Tỷ lệ nữ $/$ nam $=2 / 1$, trong đó nữ chiếm $66,7 \%$, nam chiếm $33,3 \%$.

3.2. Triệu chứng lâm sàng, cận lâm sàng

- Triệu chứng cơ năng:

Bảng 2. Đánh giá triệu chứng cơ năng

\begin{tabular}{|c|c|c|}
\hline Triệu chứng & $\mathbf{n}$ & $\mathbf{( \% )}$ \\
\hline Đau nhức mằt & 28 & $93,3 \%$ \\
\hline $\begin{array}{c}\text { Nhìn mờ, nhìn đèn có } \\
\text { quầng xanh đỏ }\end{array}$ & 27 & $90 \%$ \\
\hline Nhức đâu, buồn nôn & 4 & $13,3 \%$ \\
\hline Sợ ánh sáng & 2 & $6,7 \%$ \\
\hline
\end{tabular}

Đa số bệnh nhân có triệu chứng cơ năng như đau nhức 93,3\% và triệu chứng nhìn mờ hoặc nhìn có quầng xanh đỏ $90 \%$. Số bênh nhân có triệu chứng nhức đầu, buồn nôn chiểm $13,3 \%$ và bệnh nhân có triêuu chứng sợ ánh sáng chiếm 6,7\%.

- Triệu chứng thức thể

Khám trên kính sinh hiển vi

Bảng 3. Triêuu chứng quan sát trên kính SHV

\begin{tabular}{|c|c|c|}
\hline Triêu chứng & $\mathbf{n}$ & (\%) \\
\hline Cướng tụ rìa & 11 & $26,8 \%$ \\
\hline Giác mạc phù & 7 & $17,1 \%$ \\
\hline Tiền phòng nông & 41 & $100 \%$ \\
\hline Đồng tử giãn, phản xạ & 15 & $36,6 \%$ \\
\hline $\begin{array}{l}\text { Khi khám bằng kính } \\
\text { Glôcôm góc đóng nguyê } \\
\text { tiền phòng nông, 26,8\% } \\
\text { 17,1\% mắt có giác mạc } \\
\text { tử giãn hoặc phản xa lười } \\
\text { Thi lực trước phẫu } \\
\text { Bảng 4. Bảng đán } \\
\text { phẫu thuât }\end{array}$ & trên & $\begin{array}{l}1 \text { mắt b } \\
\text { \% mắt có } \\
\text { ng tụ rìa, } \\
\text { át có đồng }\end{array}$ \\
\hline Thi lức chỉnh kính & $\mathbf{n}$ & (\%) \\
\hline$\leq$ ĐNT $3 \mathrm{~m}$ & 6 & 14,6 \\
\hline
\end{tabular}

\begin{tabular}{|c|c|c|}
\hline$>$ ĐNT 3m $-1 / 10$ & 9 & 22 \\
\hline$>1 / 10-3 / 10$ & 13 & 31,7 \\
\hline$>3 / 10-7 / 10$ & 10 & 24,4 \\
\hline$>7 / 10$ & 3 & 7,3 \\
\hline Tống & $\mathbf{4 1}$ & $\mathbf{1 0 0} \%$ \\
\hline
\end{tabular}

Trong nghiên cứu của chúng tôi, phần lớn bệnh nhân vào viện với thị lực dưới $3 / 10$ chiếm $68,3 \%$.

Nhãn áp trước phẫu thuật

Bảng 5. Bảng đánh giá nhãn áp trước phẫu thuật

\begin{tabular}{|c|c|c|}
\hline Mức NA (mmHg) & $\mathbf{n}$ & $\mathbf{( \% )}$ \\
\hline$\leq 23$ & 30 & 73,2 \\
\hline $24-32$ & 11 & $26,8 \%$ \\
\hline$>32$ & 0 & $0 \%$ \\
\hline Tống & $\mathbf{4 1}$ & $\mathbf{1 0 0} \%$ \\
\hline
\end{tabular}

Nhãn áp của bệnh nhân khi vào viện chủ yếu $<24 \mathrm{mmHg}$ chiếm $73,2 \%$, nhãn áp trung bình 21 $\pm 3,9 \mathrm{mmHg}$.

- Cận lâm sàng

Bảng 6. Tỷ lệ C/D trước phẫu thuật \begin{tabular}{|l|l|l}
\hline Tỷ lệ lõm/đĩa (C/D) & $\mathbf{n}$ & $\mathbf{( \% )}$ \\
\hline
\end{tabular}

\begin{tabular}{|c|c|c|}
\hline$\leq 0,3$ & 6 & 16,2 \\
\hline $0,4-0,6$ & 16 & 43,2 \\
\hline$\geq 0,7$ & 15 & 40,6 \\
\hline Tống & $\mathbf{3 7}$ & $\mathbf{1 0 0}$ \\
\hline
\end{tabular}

Trong 37 mắt được chụp OCT mức độ lõm đĩa $>0,3$ chiếm $83,8 \%$, trong đó lõm đĩa rộng $\geq 0,7$ chiếm tới 40,6\%.

3.3. Kết quả sau phẫu thuật

- Thi lức sau phấu thuât

Bảng 7. Sư thay đổi thị lực sau phẫu thuật 1 tháng so với trước mố

\begin{tabular}{|c|c|c|c|c|}
\hline \multirow{2}{*}{$\begin{array}{c}\text { Thay } \\
\text { đổi thị } \\
\text { lực }\end{array}$} & \multicolumn{2}{|c|}{$\begin{array}{l}\text { Căt bè củng } \\
\text { giác mạc }\end{array}$} & \multicolumn{2}{|c|}{$\begin{array}{l}\text { Cắt mống mắt } \\
\text { chu biên }\end{array}$} \\
\hline & $\begin{array}{l}\text { Số } \\
\text { mắt }\end{array}$ & $\begin{array}{l}\text { Tỷ lệ } \\
\%\end{array}$ & $\begin{array}{c}\text { Số } \\
\text { mắt }\end{array}$ & $\begin{array}{c}\text { Tỷ lệ } \\
\text { \% }\end{array}$ \\
\hline Giảm & 0 & $0 \%$ & 0 & $0 \%$ \\
\hline Ön định & 13 & $81,2 \%$ & 20 & $80 \%$ \\
\hline Tăng & 3 & $18,8 \%$ & 5 & $20 \%$ \\
\hline Tống & 16 & $100 \%$ & 25 & $100 \%$ \\
\hline
\end{tabular}

Trong nghiên cứu của chúng tôi, sau 1 tháng không có mắt nào giảm thị lực, mắt có thị lực trên $3 / 10$ chiếm $36,6 \%$, tăng so với trước mổ (31,7\%) nhưng không đáng kể. Trong đó, 16 mắt được cắt bè củng giác mạc thì thị lực tăng chiếm $18,8 \%$, ổn định chiếm tî lệ là $81,2 \%$, tương tự trong 25 mắt laser mống mắt chu biên thị lực tằng là $20 \%$, ổn định cũng chiếm $80 \%$.

- Điều chỉnh nhãn áp sau phẫu thuật

Bảng 8. Điều chỉnh nhãn áp sau phẫu thuật sau 1 tháng

\begin{tabular}{|c|c|c|c|c|}
\hline \multirow{2}{*}{$\begin{array}{c}\text { Mức NA } \\
\text { (mmHg) }\end{array}$} & \multicolumn{2}{|c|}{$\begin{array}{c}\text { Cắt bè củng } \\
\text { giác mạc }\end{array}$} & \multicolumn{2}{|c|}{$\begin{array}{c}\text { Cắt mốt mống } \\
\text { mắt chu biên }\end{array}$} \\
\cline { 2 - 5 } & Số & Tỷ & Số & Tỷ lệ \\
\hline
\end{tabular}




\begin{tabular}{|c|c|c|c|c|}
\hline & mắt & lệ\% $\%$ & mắt & $\mathbf{\%}$ \\
\hline$\leq 23$ & 16 & $100 \%$ & 25 & $100 \%$ \\
\hline $24-32$ & 0 & $0 \%$ & 0 & $0 \%$ \\
\hline$>32$ & 0 & $0 \%$ & 0 & $0 \%$ \\
\hline Tổng & 16 & $100 \%$ & 25 & $100 \%$ \\
\hline
\end{tabular}

Sau phẫu thuật $100 \%$ mắt đều có nhãn áp điều chỉnh dưới $24 \mathrm{mmHg}$, nhãn áp trung bình là $17,4 \pm 1,1 \mathrm{mmHg}$.

Đối với 16 mắt phẫu thuật cắt bè cùng giác mạc thì nhãn áp trung bình sau mổ 1 tháng là $17,9 \pm 1,3 \mathrm{mmHg}$. Đối với 25 mắt laser mống mắt chu biên thì nhãn áp trung bình sau mổ 1 tháng là $17,2 \pm 1 \mathrm{mmHg}$

- Biến chứng sau theo dõi 1 tháng. Trong nghiên cứu của chúng tôi trên 16 mắt cắt bè củng giác mạc và 25 mắt cắt mống mắt chu biên thì trên cả 41 mắt đều chưa ghi nhận các biến chứng tại các thời điểm theo dõi.

\section{BÀN LUÂNN}

4.1. Đặc điểm chung. Trong nghiên cứu của chúng tôi từ bảng 1 thấy rằng, Glôcôm góc đóng nguyên phát hay gặp nhất ở nhóm tuổi trên 60 chiếm 73,4\%, tuổi trung bình $64,2 \pm 10,7$ tuổi. So sánh với nghiên cứu khác như Phạm Thi Thu Hà (2018) là 59,4 $\pm 12,5$ tuổi [3], Zhonghua Yan Ke Za Zhi (2019) là $59 \pm 7$ tuối [4] cho thấy kết quả tương đồng.

Cũng từ bảng 1 ta thấy nữ mắc nhiều hơn nam, tỷ lệ nữ/ nam=2/1. Kết quả phù hợp với nghiên cứu dịch tễ học thì nữ giới gặp nhiều hơn nam giới. Chúng tôi nhận thấy kết quả tương đồng khi so sánh với tác giả Lương Thị Hải Hà, Đặng Đức Minh (2019) khi nữ giới chiếm 67,3\% [5].

4.2. Đặc điểm lâm sàng, cận lâm sàng

4.2.1. Triệu chứng cơ năng. Từ kết quả bảng 2 cho thây triệu chứng hay gặp nhất đau nhức $93,3 \%$ và nhìn mờ hoặc nhìn có quâng xanh đỏ $90 \%$. Các triệu chứng khác chiếm tỷ lệ thấp lần lượt là nhức đầu, buồn nôn chiếm 13,3\%, sợ ánh sáng chiếm $6,7 \%$. Như vậy, đau nhức và nhìn mờ là hai triệu chứng cớ năng chính. Triệu chứng thường tiến triển chậm, mãn tính, nên bệnh nhân thường khó phát hiện, bệnh nhân chỉ đỉ khám khi thị lực đã giảm sút rất nhiều. Vì vậy công tác chẩn đoán và điều trị còn gặp rất nhiều khó khăn.

\subsubsection{Triêu chứng thức thể}

Khám trên kính sinh hiển vi. Từ bảng 3 chúng tôi nhân thấy tất cả bênh nhân đều có tiền phòng nồng (100\%). Như vậy, tiền phòng nông là triệu chứng chính có thể khám thây được trên kính sinh hiển vi. Điều này là phù hợp vì mắt có tiền phòng nông là một trong những yếu tố nguy cơ của Glôcôm góc đóng nguyên phát.

Thị lực trước phẫu thuật. Từ bảng 4 cho thây trong nghiên cứu của chúng tôi, phần lớn bệnh nhân vào viện với thị lực dưới $3 / 10$ chiếm $68,3 \%$. Điều này có thể giải thích do bệnh nhân không có các triệu chứng rõ ràng, tiến triển chậm nên bệnh nhân thường đến khám khi thị lực đã giảm sút nhiều.

Nhãn áp trước phẫu thuật. Từ bảng 5 cho thây nhãn áp của bệnh nhân khi vào viện chủ yếu $<24 \mathrm{mmHg}$ chiếm 73,2\%, nhãn áp trung bình 21 $\pm 3,9 \mathrm{mmHg}$. So sánh với những nghiên cứu tương tự khác trong nước, theo Phạm Tân Tiến (2008) [6], nhãn áp trung bình khi bệnh nhân nhập viện là $17,65 \pm 1,75 \mathrm{mmHg}$, nhãn áp trung bình của chúng tôi cao hơn vì tiêu chuẩn chọn bệnh nhân của tác giả là chỉ nghiên cứu trên bệnh nhân Glôcôm giai đoan tiềm tàng và sơ phát.

4.2.3. Cận lâm sàng. Từ bảng 5 chúng tôi nhận thấy, trong 37 mắt được chụp OCT mức độ Iõm đĩa > 0,3 chiếm $83,8 \%$, trong đó lõm đĩa rộng $\geq 0,7$ chiếm tới $40,6 \%$. Việc đánh giá tình trạng lõm đĩa đóng vai trò quan trọng trong việc chẩn đoán và và theo dõi tiến triển bệnh Glôcôm.

\subsection{Kết quả phẫu thuâtt}

4.3.1. Thị lực sau phẩu thuât. Từ kết quả bảng 6 cho thấy trong nghiên cứu của chúng tôi, sau 1 tháng không có mắt nào giảm thị lực, mắt có thị lực trên $3 / 10$ chiếm $36,6 \%$, tăng so với trước mổ $(31,7 \%)$ nhưng không đáng kể. Trong đó, 16 mắt được cắt bè củng giác mạc thì thị lực tăng chiếm $18,8 \%$, ổn định chiếm tỉ lệ là $81,2 \%$, tương tự trong 25 mắt laser mống mắt chu biên thị lực tăng là $20 \%$, ổn định cũng chiếm $80 \%$. Như vậy, sau khi phẩu thuật thì thị lực của bệnh nhân hầu như chỉ tăng rất ít, chủ yếu là ổn định.

4.3.2. Điều chỉnh nhãn áp sau phẫu thuật. Từ kết quả bảng 7 cho thấy sau phẫu thuật $100 \%$ mắt đều có nhãn áp điều chỉnh dưới $24 \mathrm{mmHg}$, nhãn áp trung bình là $17,4 \pm 1,1 \mathrm{mmHg}$.

Đối với 16 mắt phẫu thuật cắt bè cùng giác mạc thì nhãn áp trung bình sau mổ 1 tháng là $17,9 \pm 1,3 \mathrm{mmHg}$, theo 1 số nghiên cứu gần đây như của Nguyễn Hồ Việt Liên, Phan Văn Năm (2014) [7] nhãn áp trung bình khi ra viện 1 tháng là $16,41 \pm 3,49 \mathrm{mmHg}$ ta thấy có sự khác biệt so với nghiên cứu của chúng tôi. Có sự khác nhau như vậy do nghiên cứu của chúng tổi tỷ lệ Glôcôm góc đóng mạn tính chiếm tỷ lệ cao $(61 \%)$ trong khi nghiên cứu của tác giả Nguyễn Hồ Viêt Liên chỉ là $25 \%$.

Đối với 25 mắt laser mống mắt chu biên thì nhãn áp trung bình sau mổ 1 tháng là 17,2 \pm 
$1 \mathrm{mmHg}$. So sánh với tác giả khác như ta thấy kết quả tương đồng như Phạm Tân Tiến (2008) [6] nhãn áp trung bình sau mổ 1 tháng là 17,45 $\pm 1,49 \mathrm{mmHg}$.

4.3.3. Biến chứng sau phẫu thuật. Trong nghiên cứu của chúng tôi trên 16 mắt cắt bè củng giác mạc và 25 mắt cắt mống mắt chu biên thì trên cả 41 mắt đều chưa ghi nhận các biến chứng tại các thời điểm theo dõi.

Trong phẫu thuật cắt bè củng giác mạc, theo nghiên cứu của Nguyễn Hồ Việt Liên, Phan Văn Năm (2014) [7] thì tỷ lệ gặp biến chứng sau phẫu thuật như viêm màng bồ đào chiếm $12,5 \%$ và đục thể thửy tinh là 6,3\% sau 3 tháng theo dõi.

Trong phẫu thuật laser mống mắt chu biên theo tác giả Vũ Thị Thái, Nguyễn Thị Hà Thanh (2018) [8], nghiên cứu trên 141 mắt trong 2 năm thì cũng không có trường hợp nào bị bít hay không rõ lỗ cắt, ngoài ra cũng không gặp các biến chứng khác.

Có sự khác biệt giữa nghiên cứu của chúng tôi so với các tác giả khác là do số bệnh nhân nghiên cứu của chúng tôi là ít hơn rất nhiêu so với các nghiên cứu khác đồng thời thời gian theo dõi rất ngắn (1 tháng) nên không thể theo dõi được các biến chứng muộn sau phẫu thuật như viêm màng bồ đào hay đục thể thủy tinh.

\section{KẾT LUẦN}

1. Đặc điểm lâm sàng, cận lâm sàng

- Bệnh nhân chủ yếu trền 60 tuổi chiếm $73,4 \%$, tuổi trung bình $64,2 \pm 10,7$ tuổi. Nữ gấp đôi nam.

- Triệu chứng lâm sàng thường gặp: nhìn mờ (90\%) và đau nhức $(93,3 \%)$, tiền phòng nông
(100\%) , thị lực giảm, nhãn áp tăng

- Triệu chứng cận lâm sàng trên OCT: chủ yếu mức lõm đĩa $>0,3(83,8 \%)$.

\section{Kết quả điêu trị}

- Thị lực tăng ít hoặc ổn định

- Sau phẫu thuật nhãn áp trung bình còn

$17,4 \pm 1,1 \mathrm{mmHg}$.

- Không có biến chứng sau phẫu thuật.

\section{TÀl LIẸU THAM KHẢO}

1. Giangiacomo A, Coleman AL (2009). The epidemiology of Glaucoma.Glaucoma, Spinger, Hardcover, pp22-26.

2. Đố Như Hơn (2011). Đại cương Glôcôm, Nhãn khoa, Nhà xuất bản Y học, pp 224-235.

3. Pham Thi Thu Hà (2018). Nghiên cứu đăc điềm lâm sàng và kết quả điều trị Glôcôm ác tính, Luận văn tiến sĩ y học, Trường đai hoc Y Hà Nội.

4. Zhonghua Yan Ke Za Zhi (2019). Preliminary efficacy of penetrating canaloplasty in primary angle- closure Glaucoma. The eyes hospital of Wenzhou Medical.

5. Lương Thi Hải Hà, Đăng Đức Minh (2019). Đăc điểm rối loạn sắc giác trên bệnh nhân Glôcôm nguyên phát. Tap chí Y dược lâm sàng 108, trường đại học y dược Thái Nguyên.

6. Phạm Tân Tiến (2008). Nghiên cứu ứng dụng laser Nd:YAG với hai bước sóng khác nhau cắt mống mắt chu biên điêu trị Glôcôm góc đóng, Luận văn tiến sỹ y học, Học viện Quân y.

7. Nguyến Hồ Việt Liên, Phan Văn Năm (2014). Nghiên cứu đăc điểm lâm sàng và kết guả điều trị Glôcôm góc đóng nguyên phát bằng phâuu thuật tai Khoa Mắt Bệnh viện Trung ương Huê. luận văn bác sĩ nôi trú, trường Đ̇ai hoc $Y$ dước Huế

8. Vũ Thị Thái, Nguyến Thị Hà Thanh (2018). Đánh giá kết quả lâu dài của phẫu thuật cắt mống mắt chu biên điêu trị Glôcôm nguyên phát tại khoa Glôcôm bệnh viện Mắt Trung ương, luận vằn tiến sĩ, trường Đại học y Hà Nội.

\section{ĐÁNH GIÁ KẾT QUẢ THẨM MỸ 5 NĂM XA TRI ĐIỀU BIẾN LIỀU SAU PHẪU THUÂTT UNG THƯ VÚ BẢO TỒN GIAI ĐOẠN I-II TẠI BÊ̂NH VIỆN K}

\section{TÓM TẮT}

Ung thư vú là bênh ung thư thường găp nhất ở phụ nữ. Điều trị bảo tồn chỉ định cho giai đoạn I-II, xạ trị bổ trợ sau phẫu thuật bảo tồn là chỉ định bắt buộc.

*Bệnh viện $K$

Chịu trách nhiệm chính: Nguyễn Công Hoàng

Email: hoangdoc@gmail.com

Ngày nhận bài: 9.8.2021

Ngày phản biên khoa hoc: 4.10 .2021

Ngày duyệt bài: 14.10 .2021

\section{Nguyễn Công Hoàng ${ }^{1}$, Đinh Công Định ${ }^{2}$}

Xạ trị điều biến liều (F-IMRT) là kỹ thuật sử dụng máy gia tốc có trang bi hê thống collimator đa lá có khả năng tối ưu hóa kế hoạch xạ trị, cải thiện rõ rệt phân bố liều tai thể tích điều trị, giảm liều xa vào tổ chức lành xung quanh. Nghiên cứu nhằm nhẩn xét một số đăc điểm lâm sàng và đánh giá kết quá̉ thẩm mỹ̃ tai thời điểm 5 năm sau xạ trị điêu biến liều ung thư vú bảo tồn tại bệnh viện $K$. Đối tượng và phương pháp nghiên cứu: 68 bệnh nhân đủ tiêu chuẩn cụ thể giai đoạn I, II điều trị bảo tồn tại Bệnh viện $\mathrm{K}$ từ tháng 02/2016 đến 10/2021. Xa trị kỹ thuật điểu biến liều (F-IMRT). Nghiên cứu mô tả, tiến hành thu thập 